\title{
Havaintoja karjalaisten joikujen musiikillisesta rakenteesta
}

Karjalaisten joikujen musiikilliset erikoisuudet ovat vielä suuremmalta osaltaan selvittämättä, mikä johtuu siitä, ettei tätä erityslajia ole tutkittu paljoakaan. Tilannetta heijastavat perin harvat julkaisut, joissa on tarkasteltu tai sivuttu joiunnan erikoisuuksia. Tutkimuksen vähyys tällä alalla on toisaalta johtanut saatujenkin tietojen vajanaisuuteen ja kieroutumiseen. A. O. Väisäsen toimekkaan joskin lyhyen joikujen keräilyn jälkeen tutkimuksessa koitti pitkittynyt tauko. Joikujen tallentamista jatkettiin vasta lauluperinteen sammumisvaiheessa, jolloin esittäjiä kannusti laulamaan enää lähinnä keräilijän harras pyyntö. Lieneekö aidon lauluvirikkeen puuttumisen syytä se, että monista myöhemmistä äänityksistä ovat hävinneet refrengit (kertaumat, joissa runoteksti on useimmiten korvattu erityisillä äänillä tai tavuilla: ho, he, no, ne). Refrengien katoamiseen saattoi vaikuttaa myös laulajien korkea ikä. Se on estänyt esittämästä kertaumia, jotka laulajien kertoman mukaan kysyvät melkoisia fyysisiä ja henkisiä ponnistuksia.

Refrengien katoaminen taitaa olla näkyvin seuraus laulantaperinteen sammumisesta ja häviämisestä. Arvattavasti tuollaisia muutoksia, joita on vaikea ja toisinaan mahdotonkin huomata pelkän havainnoinnin pohjalta, voi olla useampiakin. Osa niistä tuodaan ilmi rin- 
nastettaessa toisiinsa Väisäsen ja toisaalta Karjalan tiedekeskuksen kielen, kirjallisuuden ja historian tutkimuslaitoksen työntekijöiden tekemiä äänityksiä.

Karjalaisten joikujen esitysperinteitä koskevien tietojen vajanaisuus johtuu siitäkin, etteivät monet piirteeet tule esille äänityksistä. IImentäähän jokainen esitys ainutlaatuisesti luovuutta ohjaavia prosesseja. Niiden ymmärtämiseksi tarvittaisiin kokeilua, johon osallistuisivat joiuntaperinteitä hallitsevat ja parhaassa tapauksessa alallansa pätevät henkilöt. Mutta tällainen kokeilu ei valitettavasti onnistu, sillä ainoa esitysperinteitä tunteva hengissä oleva mies Mihkali Isakov ei enää pysty auttamaan paljoakaan (hän on syntynyt vuonna 1902).

Sittenkin on toiveita, että vaikkapa osa luovuutta ohjaavista seikoista saataisiin esiin ilman tuollaista kokeilua niiden erikoisten tutkimusten avulla, jollaisiin olemme ryhtyneet. Se ei alkuaskelillaan ole vielä tarjonnut suuriakaan tuloksia, joten en sen koommin kajoa asiaan.

Siirryn esittelemään äänitysmateriaalin tarkastelun ja kuulopohjaisen nuotituksen myötä tehtyjä havaintoja.

Ennen muuta aineistossa pistää silmään kaksi tyylisuuntaa. Toista edustavat joiut, joiden laulajien syntymäkielinä olivat Uhtua, Alajärvi, Tollojoki, Kivijärvi ja Akonlahti. Ne sijaitsevat Uhtuasta lounaaseen ja kuuluvat erilaisten karjalaismurteiden levinneisyysalueisiin. Jos aineistoa olisi tarjolla runsaasti, voitaisiin varmasti havaita sellaisia yksityiskohtia, jotka erottavat sanokaamme Akonlahdessa ja Uhtuassa tallennetut joiut toisistaan. Käytössä oleva niukka aineisto taas antaa aihetta vain toteamukseen, että kaikissa noissa näytteissä on paljon enemmän yhteisiä piirteitä kuin eroja (esimerkki 1, rivit 2-4, 7, 8 sekä $6,5)$. Kyseiset joiut eroavat jyrkästi Uhtuan pohjoispuolella tallennetuista. Tätä seikkaa silmällä pitäen nimitän tarkastelun helpottamiseksi Uhtuan lounaispuolista joiuntatyyliä uhtualaiseksi.

Toinen tyyli voisi olla "kiestinkiläinen". Sitä edustavien joikujen laulajien syntymäkylät sijaitsevat Kiestingin ympärillä. Niitä ovat Häme, Katoslampi, Vaarakylä, Kokkosalmi, Sohjenansuu, Lampahaini, Jeletjärvi, Heinäjärvi, Ruva, Soukelo, Kostovaara ja itse Kiestinki. Kummankin tyylin tunnusomaisista piirteistä ovat A. Stepanova ja N. Lavonen kirjoittaneet artikkelissaan.

Musiikillisista erikoisuuksista puheen ollen todettakoon joitakin uusia havaintoja. Uhtualaisperinteiset joiut muistuttavat rakenteeltaan tavallisia lauluja. Niiden sävelkulussa on useita häälaulujen aineksia (esim. 1, rivit 1, 2). Säännöllisesti ja jaksoittain toistuvat ainekset 
Esimerkki 1.

häälauluNuokkiniemi $\delta=100$

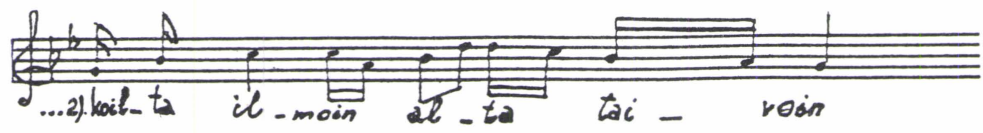

joiku/Akonlahti $\oint=120$

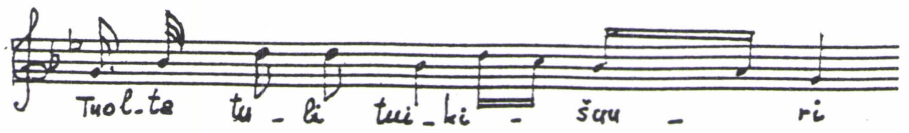

joiku/Tollojoki $\oint=92$

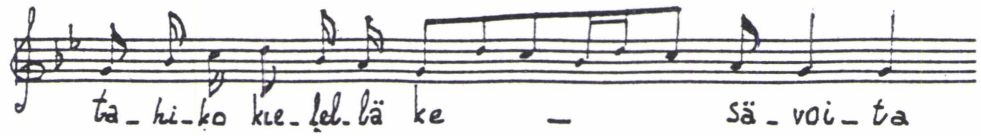

joiku/Uhtua $\oint=130$

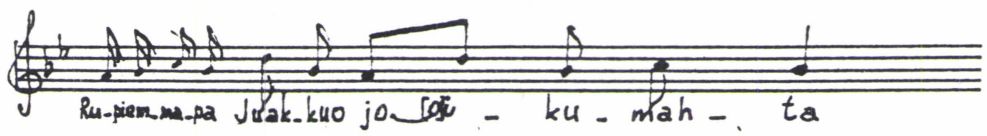

joiku/Uhtua $\oint=126$

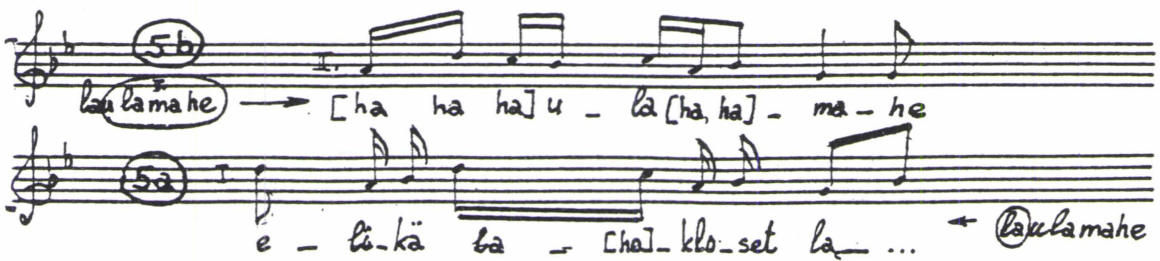

$$
\text { joiku/Alajärvi } \oint^{\prime}=120
$$

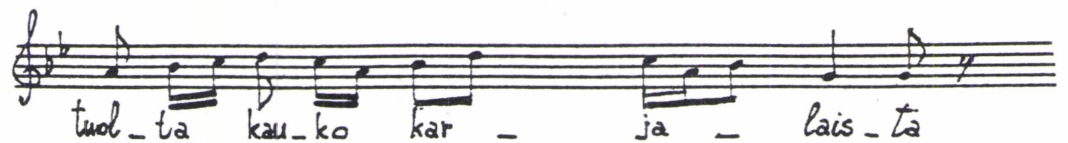




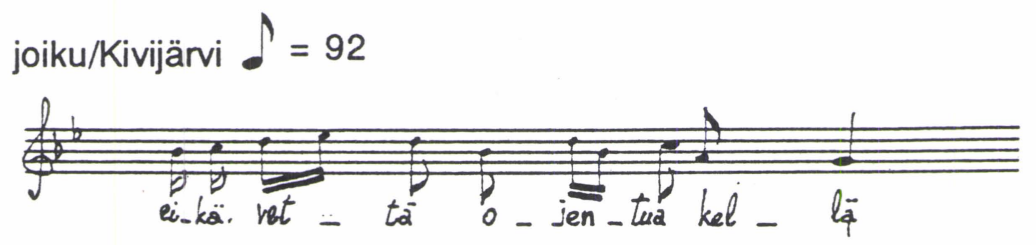

häälaulu/Uhtua $\oint=104$

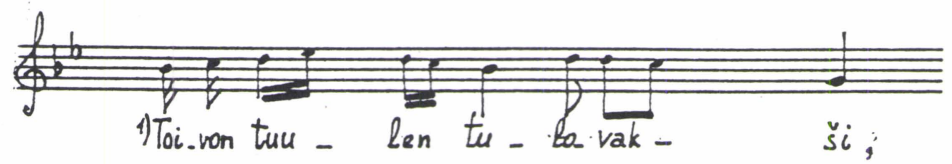

ovat käytössä olevien näytteiden mukaan yhden runorivin mittaisia (esim. 2 ja 1, rivit 3). Tuo melodiasäe säilyy perusrungoltaan ja avainääniltään. Variointia kokevat vain muutamat sävelmät (esim. 3). Tuolloin musikaalisen muotokappaleen esitysaika ei tavallisesti muutu. Uhtualaisten joikujen refrengi jäljentää useimmiten sanallista osaa. Usein tuo muotoaines puuttuu kerrassaan. (Esimerkeissä 2 ja 3 jokaista riviä seuraava sama refrengi on merkitty vain neljännellä nuottirivillä helpottamaan vertailua verbaalitekstisiin riveihin. Muut refrengit on merkitty R-kirjaimella ja refrengin sijaa osoittamalla luvulla.) Väisäsen vuonna 1915 tekemä äänitys noudattaa myös tällaista rakennetta. Hän tallensi 39-vuotiaan uhtualaisen Matrio Tikanon laulaman joiun.

Kiestinkiläiset joiut erottaa uhtualaisista ennen muuta se, että niissä rikotaan alituisesti runon, säkeen yms. lausuntaan "asetettuja" aikamittoja. Joiun sävelkulkua yhteen sitovina toistuvina aineksina esiintyvät tavuryhmää vastaavat melodiasäkeet. Runotekstin ja laulannan yhteensovittamiskeinojen tarkastelu osoittaa niiden paikallista ryhmittymistä. Niinpä Hämeen, Katoslammen, Vaarakylän, Kokkosalmen, Sohjenansuun, Kiestingin ja Lampahainin laulajat yhdistävät tavallisesti monitavuisen (aina 7 tavua) sanan tai pari kaksi- ja kolmitavuista sanaa yhteen. Monissa tapauksissa tuollainen tavuryhmä ilmaisee tyypillistä sanontaa, vertauskuvaa ja alkaa alkusoinnusta.

Melodiasäkeen alussa on koko tavuryhmälle yhteinen ja alkusoinnulliselle tavulle lankeava korotus. Korotus tehdään sekä kohottamalla äänensävyä että venyttämällä tavua. Lähelle korotusta sijoittuu usein säkeen melodinen huippu. Tavurytmin tyypilliset kestosuhteet ryhmässä voitaisiin ilmaista seuraavin suhdeluvuin: nelitavuisessa säkeessä 4:2:1:1, 3:2:1:1 tai kolmitavuisessa 4 tai 3:1:1. 
Esimerkki 2.

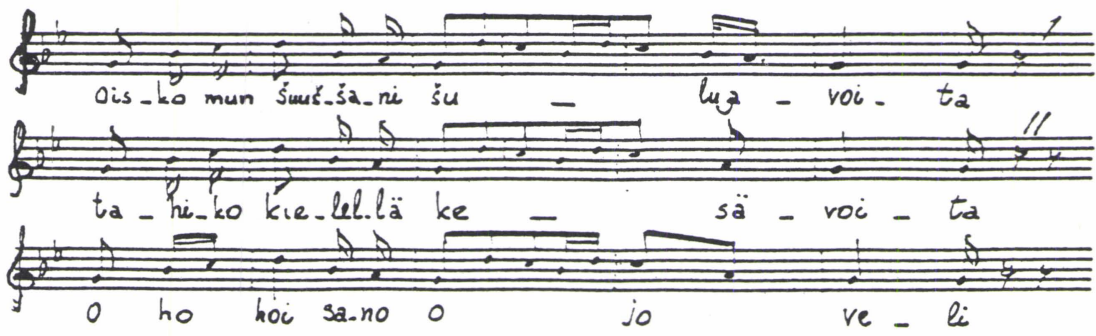

Esimerkki 3.
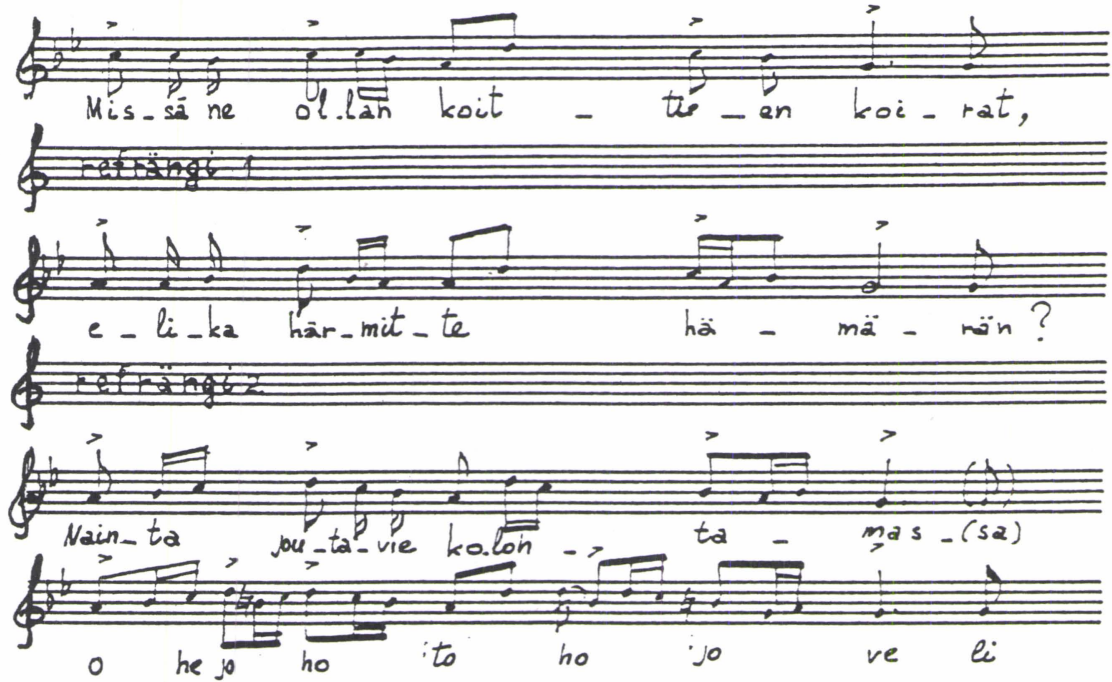

Muissa kylissä tallennetut joiut eivät noudata yhtä johdonmukaisesti tällaista rakennusperiaatetta. Tosin tarkempi tarkastelu saattaa tuoda niidenkin kesken muunlaista säännönmukaisuutta.

Joikujen mielenkiintoisimpia ja luonteenomaisimpia aineksia on refrengi. Monet A. 0 . Väisäsen lausunnot kertauman roolista joiussa ovat yhä kiinnostavia, ruokkivat mielikuvitusta ja halua rakentaa oletuksia. Hän kirjoitti: "Juuri refrengissä tahdotaan ilmentää sävelmän luonteenomaisimmat piirteet" (Väisänen 1917). Sitä paitsi hän mainitsi henkilökohtaisista joi'uista. Hänen tekemistään havainnoista päätellen henkilökohtaista sävelmää rakentava joikuja ilmaisi juuri refrengillä 
musiikillisen omaleimaisuutensa olemuksen: määräaseman saavuttaneen persoonallisuuden epäverbaalisen merkin.

Kun otetaan huomioon monenmoiset tabut, sellaiset kuin kielto laulaa naineesta, sekä pyrkimys kieli- ja vertauskuviin lähes samaan tapaan kuin virsissä ja muut samankaltaiset seikat, niin voidaan olettaa, että miltei "pääaiheeksi" korotettu informatiivinen sulhasen tai alokkaan luonnehdinta, jota esitettiin jossain vesillä tai metsässä, usein kaukana kylästä käyttäen käsittämättömiä sanoja muodostavia tavuja, ei ainakaan aikaisemmin ollut tarkoitettu kyläläisten kuultavaksi, vaan palveli eräänlaisena karsikkona. Tältä puolen saatettaisiin hyvinkin löytää kosketuksia poronleimaukseen ja muihinkin elinkeinoihin. Sanottu on kuitenkin vain joikuaineiston virittämää kuvittelua. Tuollaiset oletukset kaipaisivat tarkastelua tullakseen joko vahvistetuksi tai hylätyksi.

Paljon helpompaa on ollut selvittää ne periaatteet, joiden mukaan melodista aineistoa on valikoitu joiun sanallisesta osasta "siirrettäväksi" refrengiin. Havaintojeni perusteella voitaisiin erottaa neljä siirtymätapaa. Ensinnäkin säe jäljennetään refrengissä kirjaimellisesti tai lähes kirjaimellisesti samanlaisena. Toiseksi sävelmä niin ikään toistetaan mutta jonkin verran muunnettuna tai supistettuna. Tällöin on tärkeää, että refrengiin valitut katkelmat noudattavat samaa järjestystä kuin sanallisessa osassa. Kolmanneksi valitut kappaleet toistetaan sanallisessa osassa poikkeavassa järjestyksessä ja kovasti muunnettuina. Neljäs tapa on, kun refrengiin ei siirretä paljon mitään. Kyseiset kertaumatyypit ovat perin lyhyitä ja muistuttavat lopukkeita. Parhaissakin tapauksissa niissä voi vaivoin tunnistaa sanallisen osan sävelkulun tiivistelmän. Useimmissa tapauksissa melodinen yhteys sanallisen osan ja refrengin välillä on hämärä. Tätä kertaumatyyppiä luonnehdittaessa kannattaa mainita tavujen verrattain lyhyestä laulannasta sanallisissa osissa (esim. 2). Analogioita on kuitenkin parempi etsiä muutamien joikujen sävelkappaleiden lopukkeista, jotka rajaavat eräänlaisia melodisia sarjoja useimmiten refrengin edellä.

Aihetta tällaiseen vertailuun ovat antaneet myös viimeisten äänitysten tarkastelun parissa tehdyt havainnot. Ensinnäkin joiku kokonaisuudessaan päättyy useimmiten refrengiin ja vain harvoin alkaa siitä. Toiseksi hengitystauko osuu useimmiten refrengin ja seuraavan sanallisen osan väliin, joskin henkeä on vedettävä refrengin edellä ja keskellä sekä kaikissa mainituissa kohdissa samanaikaisesti. 
Esimerkki 4.

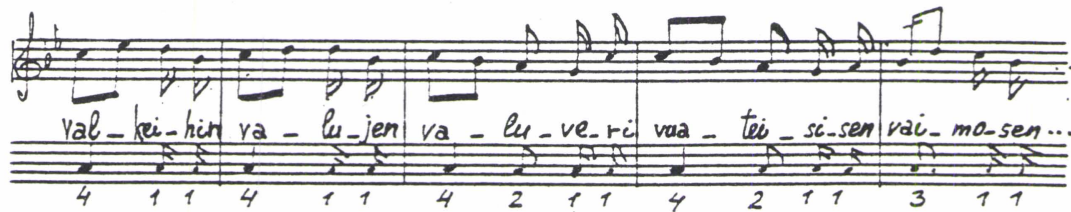

Esimerkki 5.

(R5)

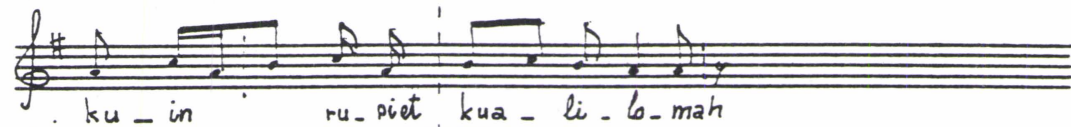

(R4)

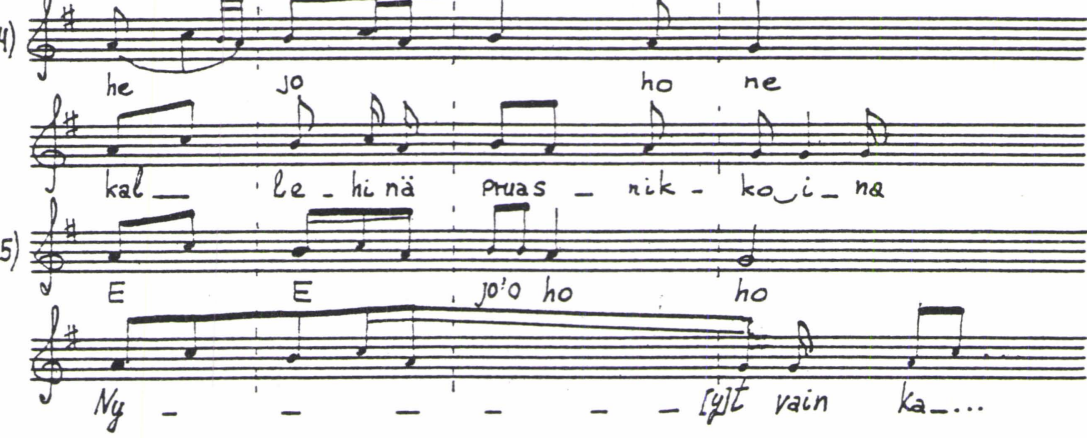

Yhteenvetona todettakoon, että mainitut joikujen sanallisen osan ja refrengin sävelmien yhteensovittamistavat luonnehtivat joikujen sävelkulkua vain yleisiltä piirteiltään. Erotetut tavat eivät selitä siirtymisprosessin muuttumista eivätkä eri ainesten vuorovaikutusta, jotka tulevat esiin esimerkiksi hirviniemeläisen Sofis Jakovlevan (synt. 1913) esittämästä joiusta. Tämän näytteen tekstissä ei kahdeksanteen riviin asti löydy hca-laulantaa sanallisesta osasta enempää kuin refrengistäkään. Tuolla rivillä se ilmestyy ja sitten toistuu eri rytmivariaatioissa riveillä 10,11 ja viimein refrengissä (rivi 12). Siitä asti tämä aines on jatkuvasti esillä ja nivoutuu elimellisesti esityksen sävelkulkuun.

Huomiota herättää refrengin vastavuoroinen vaikutus joiun sanallisen osan sävelrakenteisiin (esim. 4, rivi 16): yksitavuisen nyt -sanan laulanta toistaa lähes täydelleen sitä edeltäneen refrengin.

Esitin vain muutamia konkreettisten joikunäytteiden tarkastelun 
parissa kertyneitä havaintoja. Eihän ollut tarkoituskaan sisällyttää kaikkia yksityiskohtia karjalaisten joikujen musiikillisen tutkimuksen tilasta yleisesti kertovaan artikkeliin.

Lopuksi tekisi mieli korostaa, että erillisetkin havainnot osoittavat joiunnan musikillisen tutkimuksen tarjoavan tutkijalle mielenkiintoisia löytöjä ja varsin antoisaa materiaalia.

\section{Lähteet}

Lavonen, Nina \& Stepanova, Sandra (1992), Karjalaiset joiut. Etnomusikologian vuosikirja 4, s.142-155.

Väisänen, A.O. (1917), Vienan Karjalan joiuista. Vertaileva esitys. Aika, s.89-100. 